\title{
Economic Cost of Pedestrian Injuries in Stockholm City
}

\author{
Sandra Pahrne1, Johanna Y. Andrews Chavez², Koustuv Dalal ${ }^{3,4^{*}}$ \\ ${ }^{1}$ Karolinska Institutet, Stockholm, Sweden \\ ${ }^{2}$ Tufts University, Boston, USA \\ ${ }^{3}$ Centre for Injury Prevention and Safety Promotion, School of Health and Medical Sciences, Örebro University, \\ Örebro, Sweden \\ ${ }^{4}$ Department of Public Health Sciences, School of Life Sciences, University of Skövde, Skövde, Sweden \\ Email: koustuv2010@hotmail.com
}

Received 18 September 2014; revised 2 November 2014; accepted 17 November 2014

Copyright (C) 2014 by authors and Scientific Research Publishing Inc.

This work is licensed under the Creative Commons Attribution International License (CC BY).

http://creativecommons.org/licenses/by/4.0/

(c) (i) Open Access

\section{Abstract}

Objective: To conduct a cost analysis of pedestrian injuries at zebra crossings (marked lines only) in Stockholm city during 2008, and propose an intervention for reducing these incidents. Cost savings for the intervention are calculated and presented. Method: A Cost of Illness (COI) method was used to calculate the cost for pedestrian injuries at zebra crossings. Cost of Illness included direct and indirect costs and excluded intangible costs due to lack of data. Data and statistics from STRADA, PAR and calculations from MSB were used to perform the COI. Results: During 2008, 73 pedestrians were injured at zebra crossings in Stockholm city, amounting an estimated social cost of 10.8 million Swedish Krona (SEK) (severe injuries 9.2 million SEK, minor injuries 1.6 million SEK). The costs for reducing pedestrian injuries and related social burden via the proposed intervention (zebra crossings constructed alongside asphalt speed bumps with adjacent lights on both sides of the crossing) were estimated to be 250,000 SEK at roads without intersections, and 1.6 million SEK at roads with an intersection. Conclusion: Pedestrian injuries place a large financial burden on society each year. It is recommended to add speed bumps and adjacent lights to zebra crossings where most pedestrian injuries occur. The intervention would reduce pedestrian injuries and also decrease the cost for the society due to these injuries. Cost savings for the intervention depend on the kind of injury avoided and what kind of road the intervention is built on.

\section{Keywords}

Pedestrian Injuries, Zebra Crossing, Speed Bump, Lights, Cost, Savings, Sweden

\footnotetext{
${ }^{*}$ Corresponding author.
} 


\section{Introduction}

Globally around 16,000 people die each day from all types of injuries. Injuries represent $12 \%$ of the global burden of disease and are the third leading cause of death among 1 - 40 years old. Twenty-five percent of these deaths are from injuries that occur in road traffic. The cost for road traffic injuries (RTI) is estimated to reach roughly $1 \%$ of the GNP in low-income countries, $1.5 \%$ in middle-income countries and $2 \%$ in high-income countries [1]. Road traffic fatalities and injuries worldwide are predicted to increase by $65 \%$ between 2000 and 2020 if no new initiatives and efforts are put in place. Effective preventive strategies exist, which make the situation even more unacceptable [2].

During 2008, 18,462 road traffic crashes involving a personal injury were reported to the police in Sweden. These accidents resulted in 397 fatal injuries, 3657 severe injuries and 22,591 minor injuries. Of all road users killed in 2008, 13\% were killed in slippery road conditions and 36\% during the night, at dawn or at dusk. Pedestrians in bad lighting conditions were more likely to be killed than other road users [3]. The Swedish Civil Contingencies Agency (MSB) reported that the total societal cost for road traffic accidents in 2005 in Sweden amounted to 18.7 billion Swedish krona. In 2005, 500,000 road traffic accidents occurred, leading to 440 fatal injuries, 13,000 severe injuries, and more than 40,000 minor injuries [4].

The most vulnerable groups in road traffic are pedestrians, cyclists and motorcyclists (WHO, 2004). In 2007 in Sweden, 58 pedestrians were fatally injured (15 in Stockholm County) and 343 got severely injured (116 in Stockholm County) in road traffic collisions [4] [5]. Pedestrians have a 90\% chance of surviving a collision with a car travelling at $30 \mathrm{~km} / \mathrm{h}$ or below but only a $50 \%$ chance of surviving impacts at $45 \mathrm{~km} / \mathrm{h}$. Pedestrian and cyclist traffic have increased, as well as the fatalities of these road users, indicating an urgent need for increased attention from policy-makers [2].

Stockholm County has the highest population density in Sweden and in comparison to other counties in Sweden, many RTIs occur in this county [6]. Pedestrians are one of the groups most affected by road traffic, and further actions are needed to decrease these kinds of injuries [2]. Earlier reports have shown that the speed bump and zebra crossings with sufficient light result with speed reductions. The cost analysis of the pedestrian injuries at zebra crossings is important, particularly in Sweden where "Vision Zero", a traffic injury reduction initiative, has emphasized the importance of system design to target RTIs [7].

Since May 2000, by law, pedestrians at unmanned crossings in Sweden have priority. At these crossings, it is especially important for pedestrians to take into account the vehicle's speed and distance from the zebra crossing before entering the road. Since this law was introduced, more pedestrians have been involved in collisions with vehicles at zebra crossings [8]. Zebra crossings_-defined as painted lines only_lead to an increased risk of collisions and injuries for pedestrians and motor vehicles [9]. Potential factors explaining these collisions at zebra crossings include: motorists driving above the speed limit and unprepared to interact with pedestrians. Pedestrians are unpredictable in traffic; they can quickly change direction and decide to cross the street even though they have short time before a car enters the zebra crossing. More pedestrians cross the street where there are zebra crossings more than where there are none [10].

Studies have shown that traffic calming in cities results in reduced traffic injuries [11]. The Traffic Office in Stockholm reported that well-designed pedestrian crossings have some sorts of velocity dampening mechanism, such as a speed bump, a taper or a lateral displacement. In an experimental stretch of road with eight speed bumps, the speed of city buses and cars decreased from 49 - $60 \mathrm{~km} / \mathrm{h}$ to 25 - $34 \mathrm{~km} / \mathrm{h}$. A zebra crossing placed on a speed bump decreases accidents by 49\%. Introducing a standard zebra crossing increased pedestrian accidents by $28 \%$ [10]. Street lighting has also been suggested as an intervention to reduce traffic accidents [12]. Street light interventions are used to make pedestrians safer when they cross the street at zebra crossings. The light intervention is simple and easy to maintain compared with other interventions [13].

Zebra crossings can be safer for pedestrians; the most effective zebra crossings are those built along with a speed bump. The entire zebra crossing should be placed on this speed bump and the cars are forced to slow down before they drive over the crossing. Signs before the speed bump should be included so the car drivers know where zebra crossing speed bumps exist. Bus drivers in city areas occasionally complain that they get back pain from speed bumps, which might be a working environment concern [14]. The back pain depends on the properties of the bump, driver seat features, and the speed of the bus. There are multiple ways to constrict speed bumps. The Swedish Road Administration has reported that speed bumps positively affect vehicle speed (i.e. decrease vehicle speed), while also having indirect positive impacts on vulnerable road users' safety and 
accessibility. The report shows that speed bumps can be constructed in a way that bus drivers will not feel any back pain if they cross the bump at the right speed. Stakeholders discussing this issue have concluded that where alternatives are not reasonable, a speed bump should be constructed [15].

The objective of this study was to perform a cost analysis of pedestrian injuries at zebra crossings in Stockholm city during 2008, and propose an intervention with economic incentives for reducing injuries. The speed bump-intervention in this study can be constructed on all streets (including bus routes).

\section{Methods/Materials}

Data were collected from various sources. The primary data were collected from the Swedish Road Administration, the Swedish Civil Contingencies Agency (MSB) and the Traffic Office in Stockholm. In Sweden, a program called STRADA (Swedish Traffic Accident Data Acquisition) is used for generating information about road injuries. The system is built on information from both police and hospitals to get more accurate data about the injuries and accidents. The data from the police consist of facts such as: where the accident occurred and what they have observed, as well as the severity of the injury of the RTI victim. Data from hospitals include type of injury, severity of injury, utilization of hospital care, etc. However, STRADA data does not include information on number of days hospitalized due to RTI. For this data, the Swedish National Board of Health and Welfare has a registry program (PAR-patient register), which is similar to STRADA and includes additional information of days spent in a hospital. We have also used PAR. A literature review was conducted to acquire information regarding potential interventions. PubMed and the Cochrane database were used using search words: traffic injuries, zebra crossings, bumps, lights for intervention, pedestrians and traffic calming.

A COI was preformed to examine the cost for pedestrian injuries at zebra crossings in Stockholm city in 2008. Data from STRADA, PAR and the MSB report "Societies Cost for Road Traffic Injuries" [4] were used to calculate the COI. The data showed the severity of the injury and how many days the pedestrian was hospitalized. The analysis included average cost for both direct costs and indirect costs for the pedestrian injuries. Intangible costs were excluded due to valuation difficulties. Direct costs included: accident costs, health care costs and administration costs. Material costs were excluded due to lack of data on pedestrian injuries. Indirect costs included gross productivity cost.

Pedestrians were coded in PAR as: pedestrians injured in collision with bicycle, pedestrians injured in a collision with car or light-weight truck and pedestrians injured in collision with bus or heavy weight truck. From STRADA pedestrians that were reported and categorized as severely and minimally injured at zebra crossings were included. A person that has been categorized and reported as severely injured, is a person that has stayed at the hospital for at least one night. Out of this data, a sum of days spent in the hospital according to the severity of the injury was calculated. A combination of these data sources were used to do the cost analysis for the cost Stockholm City incurred during 2008 for pedestrians injuries at zebra crossings. Costs from MSB were presented in 2005 SEK values-the costs have been adjusted for inflation with a discount of $3 \%$ per year to get the value for 2008 SEK.

Due to lack of data, the costs reported in the results are likely to be lower than the actual costs for injuries at zebra crossings in Stockholm city during 2008. Earlier calculations regarding cost of injuries at zebra crossings do not exist; therefore, a mix of statistics has been used to calculate this cost. The cost for the proposed intervention built on roads with an intersection or roads without intersections included materials, machine rates and labour hours. Material costs included everything that is needed for the construction: asphalt, wells, lights, etc. Labour hours included hours for all persons required for the assembly. Speed bump durability depends on external factors; an asphalt speed bump typically lasts 15 - 20 years before reparation is needed. Information about the cost and what kind of materials, labour hours (including cost) and the durability of the speed bump was obtained from the Traffic Office in Stockholm.

\section{Results}

During 2008, most pedestrian injuries occurred in Stockholm. Of the 166 (90 women and 76 man) pedestrians injured in Stockholm 73 (39 women and 34 men) occurred at zebra crossings. Majority of the injuries (43\%) occurred during winter and dark seasons (November-February). Highest proportions of injuries (41\%) occurred during late afternoon and early evening (1500 - 1900). During 2008, no pedestrians were fatally injured at zebra crossings in Stockholm. Pedestrian injuries at zebra crossings resulted in 20 severe and 53 minor injuries. Young 
people (20 - 29 years) had highest proportions (38\%) of severe injuries and middle aged people (40 - 59 years) had highest proportions (28\%) of minor injuries followed by old peoples (60 years and above) severe injuries (20\%). Most of the injuries at zebra crossings in Stockholm occurred at intersections (63.4\%). The percentage of injuries at zebra crossings on roads without intersections was also high (34.2 \%). Injuries at zebra crossings in parking areas and bicycle lanes were less common (1.4\%). Table 1 presents average COI for minor injuries and Table 2 presents COI for severe pedestrian injuries at zebra crossings in Stockholm City during 2008. The tables show direct, indirect costs, and total COI is presented in total gross cost. The costs are presented in Swedish krona (SEK) 2005 values and include discounts for total cost in 2008 SEK value.

Reconstruction of zebra crossing on a road without intersections in Stockholm city costs 250,000 SEK, including working hours and materials. Reconstruction of a zebra crossing at an intersection-with four times more work load and materials—costs approximately 1.4 million SEK, excluding cost of lights. The lights cost 30,000 SEK per lamppost. The total cost for the construction of speed bumps with elevated lines (proposed crossings) with 4 bumps and 8 lights in an intersection costs approximately 1.6 million SEK (The Traffic Office, 2010).

Depending on external factors, the proposed zebra crossing intervention is generally sustained (reparations not needed) between 15 - 20 years. Annual cost without discounting the amount would be less. The fixed cost of constructing the proposed zebra crossing on a road without intersections is 250,000 SEK (50,000 after 5 years, 25,000 after 10 years, 16,667 after 15 years, and 12,500 after 20 years). The fixed cost of constructing the proposed zebra crossing at an intersection is 1,600,000 SEK (320,000 after 5 years, 160,000 SEK after 10 years, 106,667 SEK after 15 years, 80,000 SEK after 20 years). The cost savings in Table 3 presents the cost savings

Table 1. Costs for minor injuries on zebra-crossings in Stockholm city 2008.

\begin{tabular}{|c|c|c|c|c|c|}
\hline & $\begin{array}{l}\text { Cost/person (minor } \\
\text { injury) SEK value } 2005\end{array}$ & $\begin{array}{c}\text { Number of } \\
\text { persons }\end{array}$ & $\begin{array}{c}\text { Total cost in } \\
\text { SEK value } 2005\end{array}$ & $3 \%$ discount & Total cost 2008 \\
\hline \multicolumn{6}{|l|}{ Direct cost } \\
\hline Accident cost & 684 & 53 & 36,252 & $1,092,727$ & 39,614 \\
\hline Health care cost & 8090 & 53 & 428,770 & & 468,529 \\
\hline Administration cost & 7081 & 53 & 375,293 & & 410,093 \\
\hline Total direct cost & & & & & 918,236 \\
\hline \multicolumn{6}{|l|}{ Indirect cost } \\
\hline Production loss (gross) & 11,762 & 53 & 623,386 & & 681,191 \\
\hline \multicolumn{6}{|c|}{ Total COI (direct + indirect cost) } \\
\hline Total COI gross & 27,617 & 53 & $1,463,701$ & & $1,599,426$ \\
\hline
\end{tabular}

Table 2. Costs for severe injuries on zebra-crossings in Stockholm City 2008.

\begin{tabular}{|c|c|c|c|c|c|}
\hline & $\begin{array}{c}\text { Cost/person (severe } \\
\text { injury) SEK value } 2005\end{array}$ & $\begin{array}{l}\text { Number of } \\
\text { persons }\end{array}$ & $\begin{array}{c}\text { Total cost in } \\
\text { SEK value } 2005\end{array}$ & $3 \%$ discount & Total cost 2008 \\
\hline \multicolumn{6}{|l|}{ Direct cost } \\
\hline Accident cost & 1206 & 20 & 24,120 & $1,092,727$ & 26,357 \\
\hline Health care cost & 212,201 & 20 & $4,244,020$ & & $4,637,555$ \\
\hline Administration cost & 13,880 & 20 & 277,600 & & 303,341 \\
\hline Total direct cost & & & & & $4,967,253$ \\
\hline \multicolumn{6}{|l|}{ Indirect cost } \\
\hline Production loss (gross) & 195,103 & 20 & $3,902,060$ & & $4,263,886$ \\
\hline \multicolumn{6}{|c|}{ Total COI (direct + indirect cost) } \\
\hline Total COI gross & 422,390 & 20 & $8,447,800$ & & $9,231,139$ \\
\hline
\end{tabular}


Table 3. Cost savings for intervention in a straight road per minor and severe injury.

\begin{tabular}{lccccc}
\hline & $\begin{array}{c}\text { COI } \\
\text { (average per minor } \\
\text { injury) }\end{array}$ & Discounted at 3\% & $\begin{array}{c}\text { Cost for intervention; } \\
\text { intersection }\end{array}$ & $\begin{array}{c}\text { Total gross cost } \\
\text { saving }\end{array}$ & $\begin{array}{c}\text { Cost saving with 3\% } \\
\text { discount of the } \\
\text { injury cost }\end{array}$ \\
\hline \multicolumn{2}{c}{ Minor Ped Injuries } & & & & \\
1 year & 30,178 & 30,178 & 250,000 & $-219,822$ & $-219,822$ \\
5 years & 30,178 & 34,985 & 50,000 & $-19,822$ & $-15,015$ \\
10 years & 30,178 & 40,557 & 25,000 & 5,178 & 15,557 \\
15 years & 30,178 & 47,016 & 16,667 & 13,511 & 30,349 \\
20 years & 30,178 & 54,505 & 12,500 & 17,678 & 42,005 \\
\multicolumn{1}{r}{ Severe Ped Inj } & 461,557 & 461,557 & & & 211,557 \\
1 year & 461,557 & 535,071 & 250,000 & 211,557 & 485,071 \\
5 years & 461,557 & 620,294 & 50,000 & 411,557 & 595,294 \\
10 years & 461,557 & 719,091 & 25,000 & 436,557 & 702,424 \\
15 years & 461,557 & 833,623 & 16,667 & 444,890 & 821,123 \\
\hline
\end{tabular}

for preventing ONE injury with the proposed intervention constructed on a road without intersections (250,000 SEK). Cost savings is presented in average cost per minor injury (30,178 SEK) and then per severe injury (461,557 SEK). Cost savings are presented in average total gross cost (including a discount for the injuries) in relation to the intervention sustainability time (1 - 20 years).

The cost savings in Table 4 presents the cost savings for preventing ONE injury with the proposed intervention constructed at an intersection (1,600,000 SEK). Cost savings is presented in average cost per minor injury (30,178 SEK) and then per severe injury (461,557 SEK). Cost savings are presented in average total gross cost (including a discount for the injuries) in relation to the intervention sustainability time (1 - 20 years).

\section{Discussion}

Injuries cost the society significant amounts of money, and cost savings depend on whether the intervention is built on a road without intersections or at an intersection. Both proposed interventions resulted in cost savings but also depend on the type of injury that occurred.

The cost for the severely injured pedestrians was 9.2 million SEK during 2008 and the cost for minor injuries was 1.6 million SEK. Earlier calculations due to these types of injuries are not available, and costs from the MSB report [4] [5] on traffic accidents could affect the reliability of this study. Except for the material damage cost, data and statistics from STRADA and PAR matched the criteria for severely and minimally injured persons in the traffic accidents MSB report. Material damage costs were excluded from the cost analysis due to lack of data for pedestrians. The cost for injuries presented in this study is therefore smaller than the actual COI for pedestrian injuries at zebra crossings. Material damage costs are generally low for pedestrian injuries; the crash between the vehicle and the pedestrian does not damage a great deal of material. Intangible costs were also excluded in this study due to lack of data. Intangible costs are often the greatest burden during RTI; hence, the burden of injuries might be underestimated in this study. Reports and studies regarding the cost of pedestrian injuries in Sweden are limited; therefore, no comparison or validation of the presented cost could be performed. The cost for pedestrian injuries varies depending on what the cost analysis includes; this could limit the estimation of this study.

Bus drivers in Stockholm complain that their backs hurt when they drive over speed bumps in their daily work. Different opportunities are taken into account to decrease the bus drivers' exposure: limiting number of speed bumps and improving the construction of the bump. One important factor is that the bus drivers must drive at a low speed when they cross the bump, otherwise they will feel pain in their back [14]. Construction evaluations indicate that speed bumps (like the one proposed in this intervention) can be constructed in a way that the bus drivers will not get hurt during their daily work activities. It is important to think of other factors that can be improved. Ways to improve the driver and the passenger seats are also important. The proposed in- 
Table 4. Cost savings for intervention in an intersection per minor and severe injury.

\begin{tabular}{|c|c|c|c|c|c|}
\hline & $\begin{array}{c}\text { COI } \\
\text { (average per minor } \\
\text { injury) }\end{array}$ & Discounted at $3 \%$ & $\begin{array}{l}\text { Cost for intervention; } \\
\text { intersection }\end{array}$ & Total gross cost saving & $\begin{array}{c}\text { Cost saving with } 3 \% \\
\text { discount of the injury } \\
\text { cost }\end{array}$ \\
\hline \multicolumn{6}{|c|}{ Minor Ped Injuries } \\
\hline 1 year & 30,178 & 30,178 & $1,600,000$ & $-1,569,822$ & $-1,569,822$ \\
\hline 5 years & 30,178 & 34,985 & 320,000 & $-289,822$ & $-285,015$ \\
\hline 10 years & 30,178 & 40,557 & 160,000 & $-129,822$ & $-119,443$ \\
\hline 15 years & 30,178 & 47,016 & 106,667 & $-76,489$ & $-59,651$ \\
\hline 20 years & 30,178 & 54,505 & 80,000 & $-49,822$ & $-25,495$ \\
\hline \multicolumn{6}{|c|}{ Severe Ped Inj } \\
\hline 1 year & 461,557 & 461,557 & $1,600,000$ & $-1,138,443$ & $-1,138,443$ \\
\hline 5 years & 461,557 & 535,071 & 320,000 & 141,557 & 215,071 \\
\hline 10 years & 461,557 & 620,294 & 160,000 & 301,557 & 460,294 \\
\hline 15 years & 461,557 & 719,091 & 106,667 & 354,890 & 612,424 \\
\hline 20 years & 461,557 & 833,623 & 80,000 & 381,557 & 753,623 \\
\hline
\end{tabular}

tervention can be used in both commuter lanes and bus lanes.

The geographical location of the zebra crossings is not included in this study; therefore, the 73 injuries are calculated as if every injury occurred at a different zebra crossing each time. The cost savings have been calculated based on the assumption that every 1 - 20 years one injury occurs at each zebra crossing. If more injuries occur at a particular zebra crossing, the cost savings increase. The probability that more than one injury occurs at a single zebra crossing every 1 - 20 years is high and the cost saving for the society will be greater than presented. Statistics with a longer time period than one year are needed to confirm this claim. The intervention cost for an intersection might be perceived as high, except in the long run, that intervention results in large cost savings for the society, depending on how many injuries occur at one particular zebra crossing in a twenty year time period. The precise location where injuries at zebra crossings occurred could have lead to more precise cost savings calculations and a more specific proposal as to where the intervention are most needed.

Owing to varying costs, the costs presented in this study can be generalized for injuries in Sweden, but not to other countries. Cost savings showed promising results even though the calculations were average cost of prevention for one pedestrian injury during 1 - 20 years. This study presented the minimal cost saving for these interventions and nevertheless the savings were high.

Studies have shown that more pedestrians get injured when they cross the street at zebra crossings [8]. Speed bumps could help improve a law implemented in 2000 in which cars must stop and yield to pedestrians at zebra crossings. With speed bumps, the vehicles are forced to slow down when they enter a zebra crossing. This makes the interaction between the pedestrian and driver a few extra seconds longer. If crashes do occur it would result in less severe injuries because the speed of the vehicle is lower at these zebra crossing. Lights are also part of the proposed intervention, and make the zebra crossing more visible and cars more likely to notice the crossing sooner. Lights should be placed on both sides of the speed bump, and these are included in the price calculation. Travelling in darkness and speed are two factors that increase the risk for RTIs. These two factors make this intervention suitable for preventing pedestrian injuries at zebra crossings. The proposed intervention might help achieve "Vision Zero’s” milestone to reduce traffic fatalities and severe injuries by 2020.

With lights, pedestrians are more visible when they cross the street, and the surroundings area also well lit. Pedestrians will feel safe and lights for the intervention can be used for other purposes. For example, in city areas there are often streetlights beside the streets, which could decrease the cost for the intervention. In case new lights need to be installed there are often lights nearby from which to get electricity. Constructing zebra crossings on speed bumps with adjacent lights will make vehicles and buses in city areas decrease their speed and pedestrian and crossings more visible. This will be a safe GCM crossing since the speed of the vehicles will be slowed down to $34 \mathrm{~km} / \mathrm{h}$ [10] [16].

If we relate the cost of the intervention with the cost savings for these injuries, cost for the proposed interven- 
tion is low. Cost savings for preventing one severe injury with an intervention constructed at a road without intersections can save the society at least 200,000 SEK a year and almost 600,000 SEK in 10 years. Prevention for one severe injury due to the intervention constructed at an intersection can save the society 460,000 SEK in ten years. The injury costs have only been calculated for one year. In several years cost savings will be a lot greater. The cost for the intervention is only a onetime cost and this intervention is sustainable for many years. Reparations are needed every 15 - 20 years; hence, the cost savings will be greater than presented in the results. Speed bumps and lights would reduce the pedestrian injuries and decrease the cost for the society due to these injuries.

\section{Conclusion}

Pedestrian injuries place a large financial burden on society each year. It is recommended to add speed bumps and adjacent lights to zebra crossings where most pedestrian injuries occur. The intervention would reduce pedestrian injuries and also decrease the cost for the society due to these injuries. Cost savings for the intervention depend on the kind of injury avoided and what kind of road the intervention is built on.

\section{Acknowledgements}

The authors acknowledge Leena Tippana and Håkan Söderlund at Traffic Office in Stockholm and Henrik Nordin at The National Board of Health and Welfare for providing all necessary information whenever we needed.

\section{References}

[1] WHO (2004) Preventing Road Traffic Injury: A Public Health Perspective for Europe. World Health Organization, Geneva, 9.

[2] WHO (2004) World Report on Road Traffic Injury Prevention. World Health Organization, Geneva, 3, 5-6, 19-20, 35-37, 41, 71-72, 77.

[3] Saman, R. (2008) Vägtrafiksskador 2007, Statens institut för kommunikationsanalys. http://trafa.se/PageDocuments/ss2009_23.pdf

[4] Ryen, L. (2009) Samhällets Kostnader För Vägtrafikolyckor, Myndigheten för samhällsskydd och beredskap, 6-28.

[5] Ryen, L. (2009) Samhällets Kostnader För Vägtrafikolyckor—Beräkningar, Myndigheten för samhällsskydd och beredskap, 7.

[6] Vägverket (2009) Skade-Och Olycksstatistik. Vägverket, Stockholm. https://www.transportstyrelsen.se/sv/Press/Statistik/Vag/Olycksstatistik-gammal/

[7] Bergh, T., Carlsson, A. and Larsson, M. (2003) Swedish Vision Zero Experience. International Journal of Crashworthiness, 8, 159-167. http://dx.doi.org/10.1533/ijcr.2003.0224

[8] Vägverket (2004) Pedestrian and Bicycle Crossings. Vägverket, Stockholm. http://publikationswebbutik.vv.se/upload/1603/88514_pedestrian_and_bicycle_crossings.pdf

[9] Várhely, A. (1998) Drivers' Speed Behaviour at a Zebra Crossing: A Case Study. Accident Analysis \& Prevention, 30, 731-743. http://dx.doi.org/10.1016/S0001-4575(98)00026-8

[10] Welander, A.-S. (2009) Trafiksäkerhet vid övergångsställen—En kunskaps överblick. Trafikkontoret, Stockholm, 4, 30-36.

[11] Bunn, F., Collier, T., Frost, C., Ker, K., Roberts, I. and Wentz, R. (2003) Traffic Calming for the Prevention of Road Traffic Injuries: Systematic Review and Meta-Analysis. Injury Prevention, 9, 200-204. http://dx.doi.org/10.1136/ip.9.3.200

[12] Beyer, F. and Ker, K. (2009) Street Lighting for Preventing Road Traffic Injuries. Cochrane Database of Systematic Reviews Issue 1.

[13] Johansson, C. and Rosander, P. (2009) Belysningsåtgärder för oskyddade trafikanters säkerhet vid övergångsställen och gångpassager. Luleå tekniska universitet, 1, 14, 24-25.

[14] Rosander, P., Lyckman, M. and Johansson, C. (2007) Förhöjda övergångsställen för alla trafikanter—En studie om farthinder. Luleå tekniska universitet, institutionen för samhällsbyggnad, avdelningen för arkitektur \& infrastruktur, forskargruppen trafikteknik, 9, 40.

[15] Vägverket (2009) Bussar och gupp—Utgångspunkter, avsikter och fakta. Vägverket, Stockholm, 5-6.

[16] Vägverket (2009) Målstyrning av trafiksäkerhetsarbetet. Vägverket, Stockholm, 7-8, 10, 12, 34. 
Scientific Research Publishing (SCIRP) is one of the largest Open Access journal publishers. It is currently publishing more than 200 open access, online, peer-reviewed journals covering a wide range of academic disciplines. SCIRP serves the worldwide academic communities and contributes to the progress and application of science with its publication.

Other selected journals from SCIRP are listed as below. Submit your manuscript to us via either submit@scirp.org or Online Submission Portal.
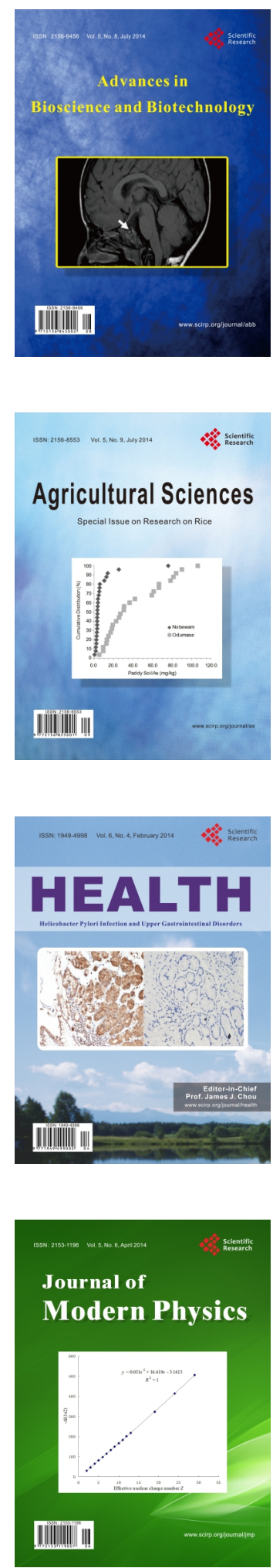
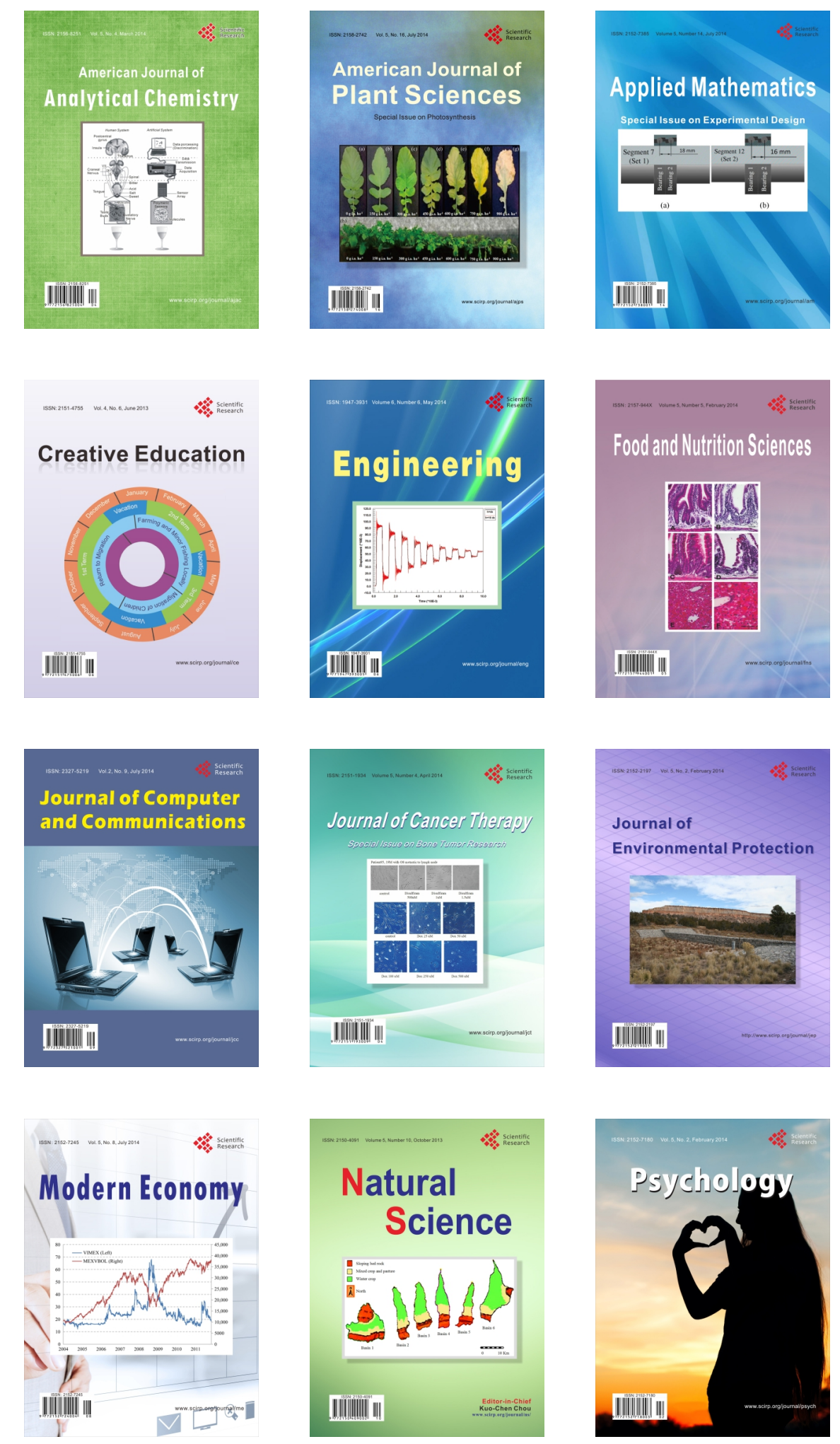